\title{
Impact of the Consequent Containment of Corona Virus on the Frequency of Aggressions in Maxillofacial and Aesthetic Surgery in Marrakesh
}

\author{
Zahira BENZENZOUM*, Nadia mansouri, M. El Bouihi, C. Opango, A. Jaifi, boukhani, Z. Aziz
}

The University Hospital Centre Mohamed VI of Marrakesh, Morocco

DOI: $10.36347 /$ sasjs.2021.v07i05.007

| Received: 29.03.2021 | Accepted: 08.05.2021 | Published: 23.05.2021

*Corresponding author: Zahira BENZENZOUM

Abstract

On January, the World Health Organization declared that COVID19 was a public health emergency with a currently known overall mortality rate which could be reach $3.4 \%$. The study is retrospective and prospective, comparing two months, 1 month before confinement and 1 month during confinement. The research was conducted within the maxillofacial surgery department of Ibn TOFAIL Hospital at Mohamed VI University Hospital in Marrakech. 1 month before the lockdown, we registered 284 assault patients, who were reported to the total admitted of 1360.1 month since the establishment of the state of emergency by the Moroccan government, encouraging confinement linked to the Covid 19 infection, we have reported 68 cases of aggression on a global workforce of 360 patients. Since the declaration of confinement in the world as a mode of prevention of COVID-19 infection in the great majority of countries, it has been observed a huge decrease in the number of road accidents, assaults and violence among which maxillofacial aggressions. COVID-19 is a disease of recent onset and very rapid spread that has traced an indisputable impact on the health profile in the world.

Keywords: Corona virus, containment, agression, maxillo-facial.

Copyright $\odot 2021$ The Author(s): This is an open-access article distributed under the terms of the Creative Commons Attribution 4.0 International License (CC BY-NC 4.0) which permits unrestricted use, distribution, and reproduction in any medium for non-commercial use provided the original author and source are credited.

\section{INTRODUCTION}

Since December 2019, China has quickly become the epicenter of a public health crisis [1] that has spread exponentially to other parts of the world, COVID-19 infection. On January 30, 2020, the World Health Organization (WHO) declared that the widespread spread of SARS-CoV-2 and its associated disease (COVID19) was a public health emergency with a currently known overall mortality rate which could be reach $3.4 \%$ [2, 3]. In the absence of a unanimous remedy, social isolation or confinement has remained a preventive measure adopted by most nations in these times of pandemic. However, this confinement is accompanied by a resurgence of cases of trauma by aggression within and outside families [4] some of which at the facial level, which justifies our study. The purpose of this study is to assess the CMF aggressions profile during this COVID-19 crisis and come up with recommendations related to the change that accompany the confinement.

\section{METHODS}

The study is retrospective and prospective at the same time, comparing two months, 1 month before confinement and 1 month during confinement. The research was conducted within the maxillofacial surgery department of Ibn TOFAIL Hospital at Mohamed VI University Hospital Center in Marrakech. It concerned 2 groups of patients, all received in the emergency maxillofacial surgery box for facial trauma by aggression.

The first group of patients from a series of 1360 trauma from all causes confounded, and all admitted from February 17 to March 17, 2020 (before confinement), the 2nd group from a series of 360 patients received from March 17 to April 172020 (during containment). Among the epidemiological and clinical parameters of the study relate to age, sex, type of lesion, origin of the patient, and place of attack and place of treatment.

\section{RESULTS}

1 month before the lockdown, we registered 284 assault patients, who were reported to the total admitted of 1360 , which representing $20.8 \%$ of the activity of the maxillofacial emergencies.

1 month since the establishment of the state of emergency by the Moroccan government, encouraging 
confinement linked to the Covid 19 infection, we have reported 68 cases of aggression which represented $17.9 \%$ of all emergency admissions maxillofacial on a global workforce of 360 patients.

A comparison of these figures finds a notable 1.6-fold increase in injuries from domestic assaults at the cost of a 1.2-fold drop in the overall workforce for all assaults, but also for road accidents.

A comparison of these figures reveals a noticeable increase of about 1.6 times of the traumatisms that results from domestic aggressions in opposite to a decrease of about 1.2 times for all kind of assaults, but also for road accidents.

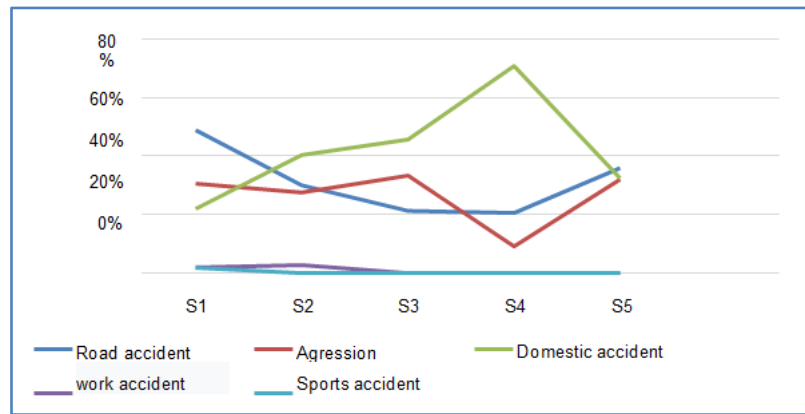

Fig-1: Evolutionary profile of the etiology of facial lesions according to the weeks during the confinement linked to the COVID 19 infection

During the period of consequent confinement of the coronavirus, the circumstances of trauma due to assault varied: $13 \%$ of the cases occurred during a robbery, $19.1 \%$ resulted from domestic violence and a brawl in $67.9 \%$. The place of assault was outside the family home in $80 \%$ of the cases but also within families in $20 \%$ of the cases.

These assaults mainly consisted in domestic and family violence, which increased by 3.2 times during the lockdown period, it means 13 assault cases out of 68 with a percentage of $19.1 \%$ in comparison to the month before confinement where domestic assaults represented only $5.9 \%$ of all cases admitted to maxillofacial emergencies, all assaults combined with respective figures of 17 cases out of 284 .

The population of patients originates exclusively from Marrakech during the COVID-19 (Chart 1), predominantly male in both periods (Chart 2), characterized by a significant difference in the female population of $10 \%$ between the 2 periods, and an average age of 30.5 years during the confinement in contrast to 27.33 years before confinement (Chart 3 ).

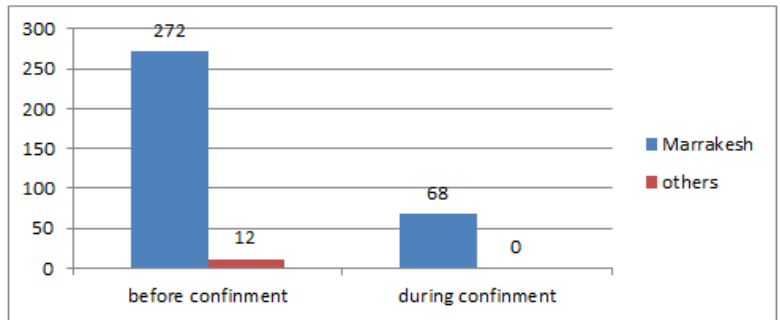

Graph-1: Distribution of patients according to their origins

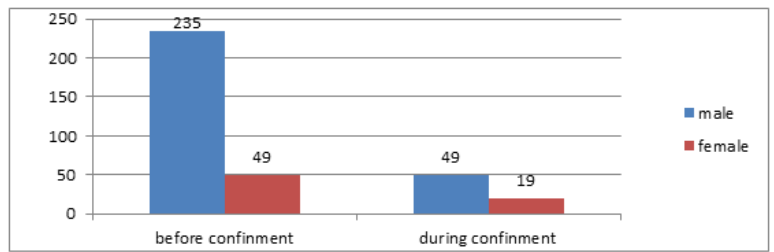

Graph-2: Distribution of patients by sex before and after confinement

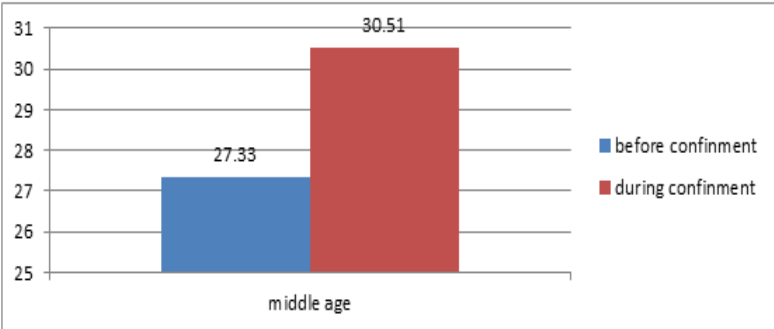

Chart-3: distribution by average age of patients

At the lesional level, the overall epidemiological profile caused by the assault during the confinement period was marked by a reduction in the number of benign facial trauma injuries by 1.5 with an increase in zygomatic fractures of 2.5 times and fractures of clean bones of the nose, mandible and dental alveoli (Chart 4).

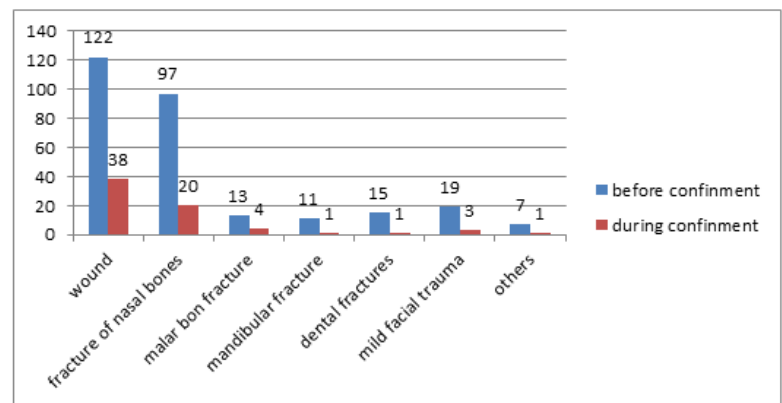

Chart-4: Distribution of the most encountered pathologies according to their type 


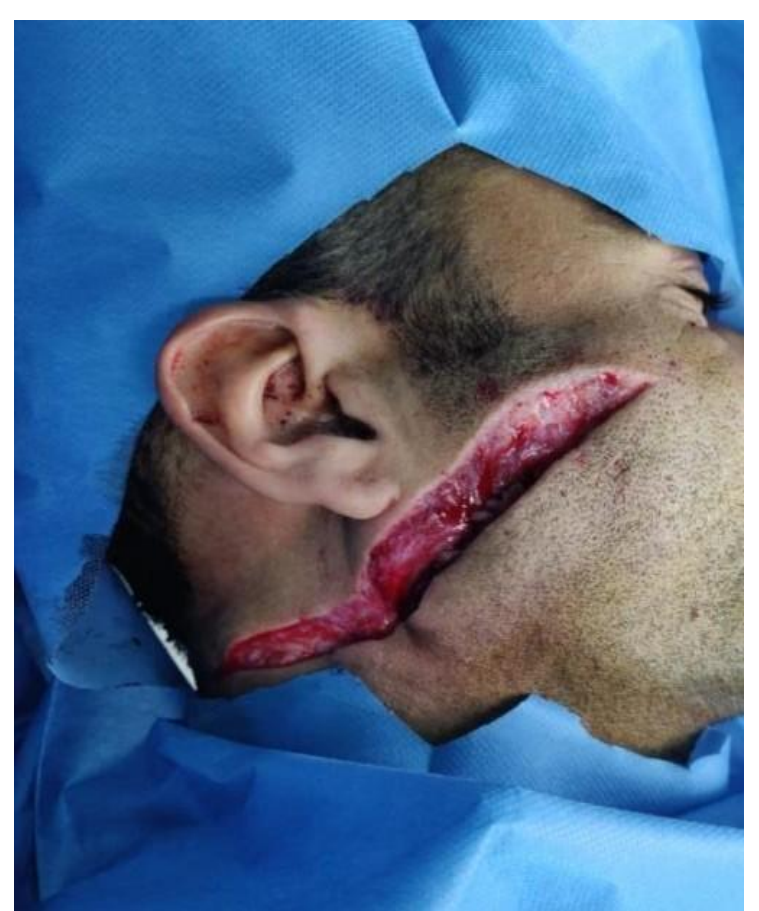

Iconography -1: Right cervico-jugal wounds with a knife in the COVID-19 period Per operative view before repair

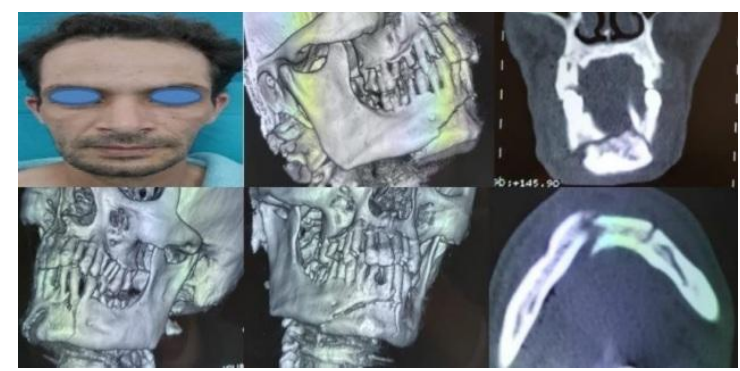

Iconography-2: displaced bifocal symphyseal Mandibular fracture in a patient victim of domestic aggression during COVID 19 period

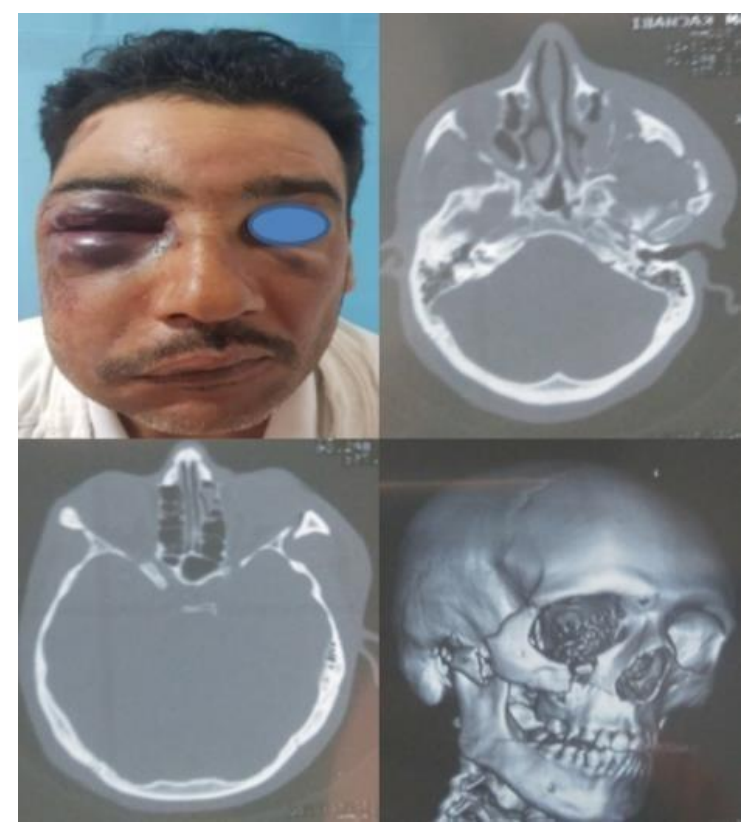

Iconography-3: Displaced fractures of the right malar bone and zygomatic arch by Aggression outside the family home during the Covid period
As for the patients' care, the operating room was preferred to the emergency room during the confinement period that means taking care of $85 \%$ in the operating room during confinement and $63 \%$ before confinement (Chart 5).

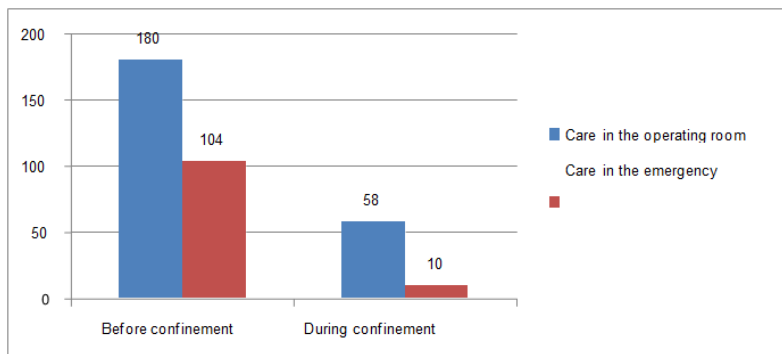

Chart 5: The distribution according to the treatment in the operating room

\section{DISCUSSION}

Since the declaration of confinement in the world by the WHO as a mode of prevention of COVID19 infection in the great majority of countries, it has been observed a huge decrease in the number of road accidents, assaults and violence [5, 6] among which maxillofacial aggressions, which is consistent with our study that revealed a reduced number at a ratio of one in 5 .

This is due to the societal change forced by the state of emergency, along with the ban on gatherings, as well as an important reduction of illicit products consumption (alcohol, drugs ...) with a drop in crime which was reported in the Washington study asserting a complete and very noticeable drop in crime, during confinement, of up to $40 \%$ [7].

However, one can notice a global increase in domestic violence cases since the installation of social isolation and quarantine policies. This increase was reported by the first observations from China with an increase of complaints of about 3 times filed at the police station comparing Feb 2019 and Feb 2010 and in Australia with a 5\% increase in calls related to domestic violence. Google has reported a $75 \%$ increase in the number of searches on the internet for "spousal abuse" [8].

In the United States, the National Domestic Violence Hotline indicated that they received several calls related to COVID-19. In France, the interior ministry speaks of an increase of more than $30 \%$ in domestic violence since the beginning of confinement.

Similarly, the number of calls to hotlines in countries like Malaysia and Lebanon has doubled compared to last year. In China, they have even tripled, according to the Chinese online magazine The SixthTone, cited by the United Nations Entity for Gender Equality and the Empowerment of Women (UN Women). 
In India, the National Commission for Women reports doubling of complaints in the first week of restrictions [9]. This violence also spotted home confinement adopted in Morocco and Marrakech. It influenced the maxillofacial lesional profile by domestic assault reported in our study, which affected more women and generated more complex lesions, dominated by more complex facial wounds, mandibular zygomatic fractures and bones of the nose.

This observation reported in this study in Marrakech, during the COVID-19 period, can be linked to several factors: economic stress, instability related to the COVID-19 pandemic, but also to the social isolation measures implemented in order to limit the spread, which exacerbate personal and collective vulnerabilities while limiting the access to any support option [10].

To prevent this domestic abuse, several associations as well as the government have mobilized, and they have announced the implementation of several systems, starting with the launch of an awareness campaign for the general public, setting up of platforms accommodation for the perpetrators of violence and listening cells like of the cell of the Mohammed VI $\mathrm{CHU}$ and the Marrakech region made available for this purpose $[11,12]$.

In these circumstances of the Covid 19 pandemic, we also emphasize, apart from social preventive measures, the need to set up adequate sanitary measures for surgical management with a more elaborate procedure for this trauma by facial assault, in order to reduce the waiting and contact time at the emergency level and the duration of care. This prompted us to favor more care in the operating room for all our emergencies and to limit ambulatory surgery in the emergency room to protect patients and caregivers with a ratio of $3.1 \%$.

\section{CONCLUSION}

COVID-19 is a disease of recent onset and very rapid spread that has traced an indisputable impact on the health profile in the world among others the trauma by domestic maxillofacial aggression particularly accentuated in this period Covid 19. It requires attention and a management strategy aimed at limiting patient exposure, which was reported in the study. Let us stay confined, and respect hygiene.

\section{REFERENCES}

1. Centers for Disease Control and Prevention Transmission of coronavirus disease; 2019 (COVID-19). Availableat: https://www.cdc.gov/coronavirus/2019ncov/about/transmission.html, Accessed 18th Mar 2020. Google Scholar.

2. Sohrabi C, Alsafi Z, O'Neill N, Khan M, Kerwan A, Al-Jabir A, Iosifidis C, Agha R. World Health Organization declares global emergency: A review of the 2019 novel coronavirus (COVID-19). International journal of surgery. 2020 Apr 1;76:716.

3. WHO director-general'sopeningremarks at the media briefing on COVID-19 - 3 March 2020. Available at:https://www.who.int/dg/speeches/detail/whodirector-general-s, opening-remarks-atthe-mediabriefing-on-covid-19, 3-march-2020, Accessed11th Mars 2020. Google Scholar

4. Nishiura H, Jung SM, Linton NM, Kinoshita R, Yang Y, Hayashi K, Kobayashi T, Yuan B, Akhmetzhanov AR. The extent of transmission of novel coronavirus in Wuhan, China, 2020.

5. Kim Usher, NavjotBhullar, JoanneDurkin. Familyviolence and COVID-19: Increased vulnerability and reduced options for support.

6. Covid19hashalvedCalifornia'strafficaccidents.April 18,2020. ByMarcBain2020QuartzMedia.

7. Neetu John, Sara E Casey, Giselle Carino, Terry McGovern. Lessons Never Learned:Crisis and gender-based violence. 25 Mars2020.

8. ABC News Australia. Retrieved on $10^{\text {th }}$ April, 2020 from: https://www.abc.net.au/news/2020-0408/coronavirus-shutdown-sees-crime-ratedropinwa/12132410.

9. COVID-19: l'ONU alarmée par la flambée des violences domestiques.

10. Coronavirus: quelssont les risques du confinement pour notre santémentale www.francetvinfo.fr/ Santé/ Maladie/ Coronavirus

11. www.ouest-france.fr/violoences conjugales.

12. Mediapart le confinement renforce les violencesconjugales par sophieboutboul,article 25 mars 2020 . 


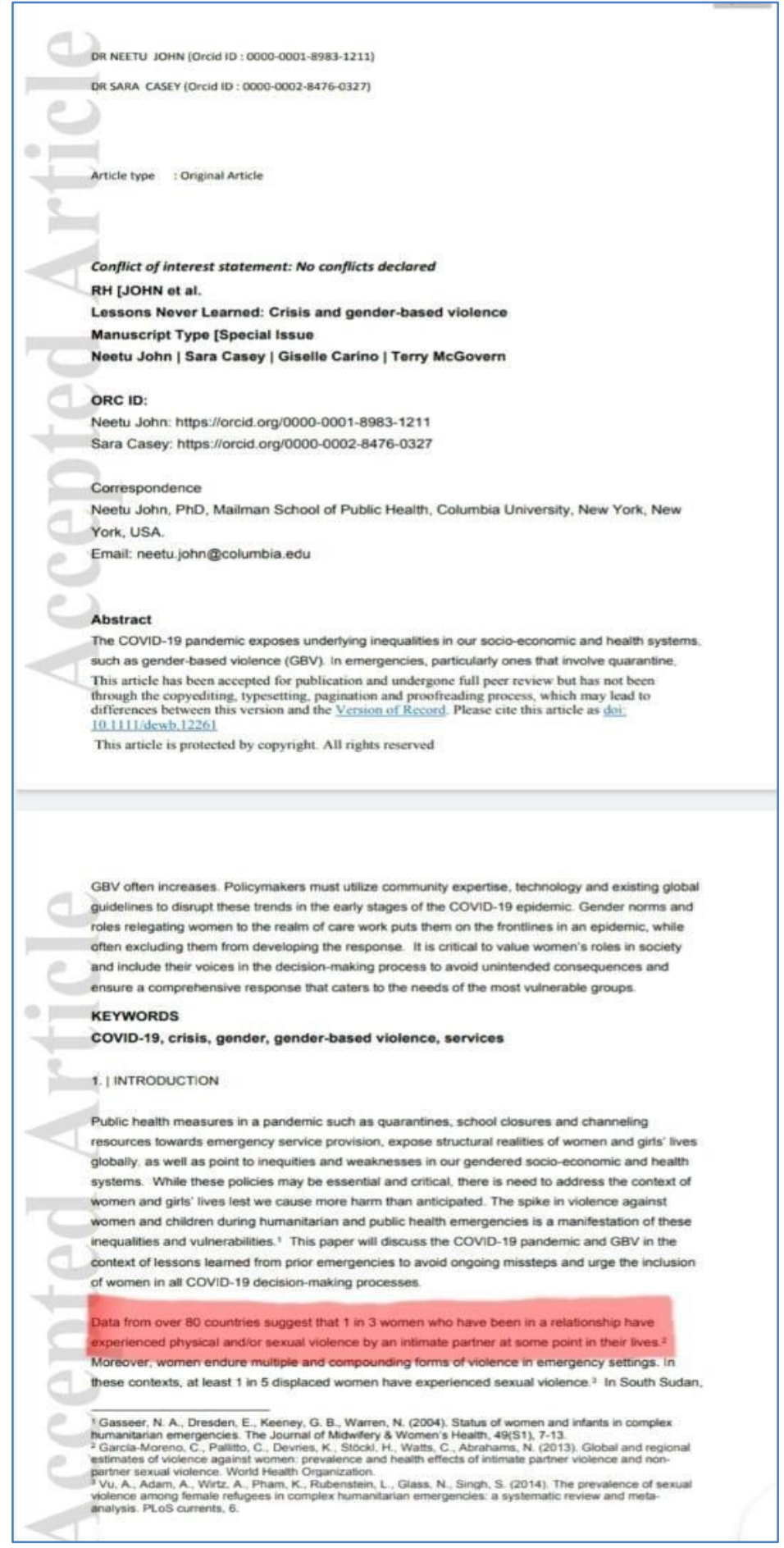

Example of an article showing the increase in spousal assaultduring confinement, Neetu John, Sara E Casey, Giselle Carino, Terry McGovern Lessons Never
Learned: Crisis and gender-based violence March 25, 2020 [7]

\section{Graph 4:------ Graph 4:}

